\title{
Assessing the Prevalence of Dyslipidemia in Apparently Healthy Urban Obese Adults Residing in South Delhi, India
}

\author{
Harmeet Kaur ${ }^{1}$, Bani Tamber Aeri ${ }^{1 *}$ \\ ${ }^{1}$ Department of Food And Nutrition, Institute of Home Economics, University of Delhi, \\ New Delhi, Delhi India 110016, India
}

\begin{abstract}
The present research study was conducted to assess the prevalence and pattern of dyslipidemia in apparently healthy urban obese adults residing in South Delhi. Dyslipidemia and obesity are two prominent contributing risk factors for cardiovascular disease. This cross-sectional study was conducted among 150 apparently healthy obese adults with a body mass index of $\geq 25 \mathrm{~kg} / \mathrm{m}^{2}$. Data regarding the socio-demographic characteristics as well as anthropometric parameters were collected. To evaluate serum lipid levels fasting blood samples were collected by trained technicians and analysis was carried out in a certified laboratory. Dyslipidemia was defined as the presence of hypercholesterolemia, high levels of Low-Density Lipoprotein (LDL) cholesterol, and /or lower concentration of High-Density Lipoprotein (HDL), present alone or in combination. The overall prevalence of dyslipidemia was noted to be $78 \%$. The prevalence was observed to be much higher in the obese female subjects $(81.43 \%)$ than the obese males (75\%). Mean triglycerides levels were significantly higher in the obese men than females while, HDL-C levels were higher in the female subjects $(\mathrm{p}<0.05)$. Further, it was seen that low concentration of HDL was the most prevailing deranged lipid parameter $(52.67 \%)$ followed by elevated triglycerides levels $(49.33 \%)$ and elevated LDL levels $(39.33 \%)$ in these obese adults. The study thus highlights the importance of regular and timely screening for apparently healthy populations. Advocating suitable and timely medical and dietary interventions can help in both monitoring and avoiding further health-related complications.
\end{abstract}

Keywords: cholesterol, dyslipidemia, high-density lipoprotein, obesity, the prevalence

\section{INTRODUCTION}

World Health Organization defines overweight and obesity as 'abnormal or excessive fat accumulation that may impair health' (WHO, 2019). Obesity is an independent risk factor for dyslipidemia, Type2 Diabetes, and Coronary artery disease and is rising in prevalence throughout the developed and developing countries (Jacob et al. 2014). In India obesity is emerging out to be a major health threat.

In India, the prevalence of obesity is increasing rapidly. In urban areas, the prevalence of obesity ranges from $13-50 \%$ while in rural areas the prevalence rate ranges from $8 \%$ to $38 \%$ (Mahajan \& Batra 2018). According to the National Family Health Survey -NFHS-4 (20152016) data the prevalence of obesity in India among adults (15-49 years) is reported to be $20.6 \%$ in women and $18.9 \%$ in men (IIPS 2017) . In Delhi, the prevalence rate is much higher than the national prevalence $(33.5 \%$ and $26.4 \%$ among women and men respectively). According to ICMR-INDIAB study, the prevalence of obesity and central obesity varied from $11.8 \%$ to $31.3 \%$ and $16.9 \%-36.3 \%$ respectively across three states and one union territory in India (that is, Jharkhand, Maharashtra, Tamil Nadu \& Chandigarh respectively; Pradeepa et al. 2015).

The rising prevalence is associated directly with obesity-related co-morbidities like highblood pressure, metabolic syndrome, dyslipidemia, diabetes mellitus (type 2), and cardiovascular disease (Jacob et al. 2014; Dewi 2007). Aberrations related to cholesterol lipoproteins such as elevated cholesterol, VLDL, LDL and triglycerides and/or low HDL levels are major risk factors related to Coronary Heart Disease (CHD) (Gupta et al. 2017). Dyslipidemia, a group of biochemical disorders, is frequently encountered in obese individuals (NCEP 2002). Dyslipidemia is defined as the presence of any of the lipid

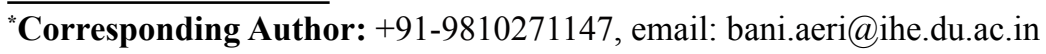


aberrations existing alone or in the combination that is: elevated levels of TC or LDL-C or serum TG or a lower level of HDL-C" (Chandra et al. 2014).

Abnormalities in lipid metabolism are very common in individuals who are obese. Approximately 60-70 percent of patients with obesity have dyslipidemia (Feingold \& Grunfeld 2000). Obesity-associated dyslipidemia undoubtedly plays a significant role in the development of atherosclerosis as well as CVD in obese individuals (Howard et al. 2003). Obesity, a modern world pandemic, is closely linked to dyslipidemia, which is mainly driven by the effects of insulin resistance and proinflammatory adipokines. Nevertheless, recent evidence indicates that obesity-induced dyslipidemia is not a single pathophysiological phenomenon, but has unique characteristics depending on many varying factors (Vekic et al. 2019). Elevated levels of triglycerides and low levels of HDL-C are metabolically interrelated. Amongst South Asians, this metabolic phenomenon is further associated with elevated levels of small LDL particles regardless of comparatively normal levels of LDL-C (Bilen et al. 2016). This is accompanied by a common metabolic derangement known as 'atherogenic dyslipidemia'(Patel et al. 2010; Sharobeem et al. 2007; Enas et al. 1996; Misra \& Khurana 2010).

The aim of the present study was thus to assess the prevalence and pattern of dyslipidemia in apparently healthy obese adults in the urban population of South Delhi.

\section{METHODS}

\section{Design, location, and time}

The present cross-sectional study was conducted in South Delhi, India. Participants were recruited from South Delhi by holding health camps at different locations after taking necessary permissions from the concerned authorities which were primarily Resident Welfare Association (RWA) of the localities. These health camps were organized with the help of RWA's and local health practitioners of the concerned areas. Purposive sampling was done to recruit apparently healthy obese adults who volunteered to be part of the study based on the inclusion criteria. The data were collected from November 2016 to September 2017.

\section{Sampling}

The present cross-sectional data is a part of another ongoing study that is being conducted on 400 subjects. Data from a sub-sample in relation to dyslipidemia is being reported here for 150 apparently healthy, free-living; obese adults comprising of both males and females. The sample size for the present study was determined using formula:

$$
\begin{gathered}
n=z^{2} p(1-p) / d^{2} \\
Z^{2}=(Z \alpha+z \beta)^{2}=95 \%
\end{gathered}
$$

p: Prevalence $(10 \%)$ (Prevalence of dyslipidemia in Indian adults $=10 \%$, (Ranganathan et al. 2015; Misra et al. 2004).

The apparently healthy obese adults belonging to the age group of 35-50 years who were willing to participate in the study were recruited. Previous studies indicate that the cardiometabolic risk factors are high in middleaged adults therefore this age range was selected. Further, obese individuals are often at a higher risk of developing cardiometabolic disorders and thus their dyslipidemia treatment is often indicated. So, it is important to assess the cardiometabolic risk among these subjects.

Subjects with a history of any chronic disease like hypertension, diabetes, etc. or those on medications for hypertension, diabetes or dyslipidemia; as well as pregnant and lactating women were excluded from the study.

\section{Data collection}

Information related to socio-demographic characteristics like gender, religion, age, family set up and marital status was collected using a pre-tested self-administered questionnaire.

Anthropometric measurements. Weight and height were taken following standard procedures. Weight was taken using a calibrated electronic bathroom scale. To assess the accurate weight of the participants, it was ensured that the shoes and any heavy clothing were removed. They were asked to remove other heavy objects on them or any such things in their pockets (like mobile phones, wallets, coins, heavy jewellery, watches, etc.). Weight was measured first thing in the morning before breakfast when subjects were in fasting state. For measuring height, commercial stadiometer was used. Height was measured using standard protocols in centimetres (to the nearest $0.1 \mathrm{~cm}$ ). Obesity was defined using Asian criteria 
to define obesity i.e. BMI of $\geq 25 \mathrm{~kg} / \mathrm{m}^{2}$ among both the genders (Misra et al. 2009).

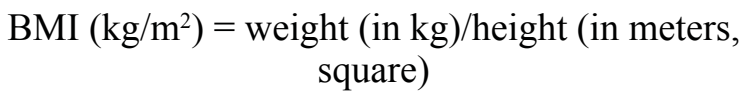

The non-stretchable fibre-glass tape was used to measure the waist and hip circumference to the nearest $0.1 \mathrm{~cm}$. ference to the nearest $0.1 \mathrm{~cm}$.

Hip circumference. Was measured at the maximum width of the buttocks and the waist measurement was taken at the point which is midway between the inferior margin of the last rib and the crest of the ileum in a horizontal plane passing the tape snugly but not tightly. All anthropometric measurements were taken twice and the mean of the two readings was used for analysis. Using anthropometric measures, anthropometric ratios like 'waist to hip' and 'waist to height' ratios were calculated using standard formulas:

$$
\begin{aligned}
& \text { Waist to hip ratio = waist circumference }(\mathrm{cm}) / \\
& \text { hip circumference }(\mathrm{cm}) \\
& \text { Waist to height ratio = waist circumference }
\end{aligned}
$$

$$
(\mathrm{cm}) / \text { height }(\mathrm{cm})
$$

For both male and female subjects, 0.5 was used as reference cutoff for the waist to height ratio (Ashwell \& Gibson 2016) and WHOAsian cutoffs that are, 0.85 and 0.90 were used as reference cutoffs for the waist to hip ratio for female and male subjects respectively (WHO 2011)

Biochemical assessments. Blood samples of the study participants were withdrawn after overnight fasting $8-10$ hours by a trained technician and the analysis was carried out under standardized procedures in a wellestablished ISO 9001: 2001 certified laboratory. Lipid parameters were determined using the following methods: 1. Cholesterol-CHODPAP method: The concentration of serum total cholesterol was determined by modified Roeschalu et al. 1974. Principle Cholesterol esterase converts cholesterol esters to cholesterol and fatty acid. Cholesterol Oxidase (CHOD) and Peroxidase (POD) catalyses the conversion of cholesterol and hydrogen peroxide to red colour quinoneimine dye. The absorbance of quinoneimine measured at $505 \mathrm{~nm}$ is proportional to cholesterol concentration in the specimen; 2. Triglyceride-GPO Trinder method: The serum triglyceride was determined by the enzymatic method, employing lipoprotein lipase, glycerol kinase, Glycerol Phosphorase Oxide (GPO) and peroxidase (McGowan et al. 1983); 3. HDLPhosphotungstic acid and $\mathrm{Mg} 2+$ ions directly precipitate low-density lipoprotein \& VLDL and can then be extracted by centrifugation. HighDensity Lipoprotein (HDL) remain supernatant. HDL cholesterol is estimated in the supernatant, using cholesterol working reagent, by a series of enzymatic reactions which are induced by the cholesterol oxidation into Cholestenone by cholesterol oxidase, followed by the formation of hydrogen peroxide. Further, 4-aminoantipyrine and phenol react with hydrogen peroxide to form red-coloured quinoneimine in a second reaction catalysed by peroxidase (Burstein \& Allison 1970); 4. LDL- LDL cholesterol was estimated by the Friedewald calculation from fasting measurements i.e,

$$
\mathrm{LDL}=\mathrm{TC}-(\mathrm{HDL}+\text { Triglycerides } / 5)
$$

(Friedewald et al.1972)

Dyslipidemia. Dyslipidemia was defined as' a presence of any of the abnormalities, occurring alone or in a combination-increased concentration of TC or LDL-Cor serum TG or a decreased concentration of HDL-C' using NCEP (2002) guidelines: 1. Hypercholesterolemia - cholesterol levels (serum) of $\geq 200 \mathrm{mg} / \mathrm{dl} ; 2$. Hypertriglyceridemia-triglyceride levels (serum) of $\geq 150 \mathrm{mg} / \mathrm{dl}$; 3 . Low HDL cholesterol - HDL cholesterol levels of $<50 \mathrm{mg} / \mathrm{dl}$ for femlaes and $<40 \mathrm{mg} / \mathrm{dl}$ for males; 4. High LDL cholesterol - LDL cholesterol levels of $\geq 130 \mathrm{mg} / \mathrm{dl}$ calculated using the Friedwald's equation.

Ethical approval. The study protocol was approved by the Institutional Ethics Committee, Institute of Home Economics, University of Delhi (Ethics No: IHE/2016/Ethics/018). Written informed consent was taken from all the participants in English as well as in Hindi.

\section{Data analysis}

Data were double entered in Microsoft Excel 2007. For statistical analysis of the data Statistical Package for Social Sciences (SPSS) version, 25 was used. A two-tailed 'p' value was used for calculating statistical significance; a value of $p<0.05$ was taken to be significant. Descriptive statistics were calculated for 
quantifiable variables (means and standard deviation). Comparison of means between the male and female participants was done using the $\mathrm{t}$-independent test. For assessing the significance of the categorical variables chi-square value was computed.

\section{RESULTS AND DISCUSSION}

The socio-demographic characteristics of the study participants revealed that out of the total study subjects enrolled $(n=150), 53 \%(n=80)$ were males and $47 \%(n=70)$ of the subjects were females. The mean age of the study participants was $41.36 \pm 4.75$ years (viz. $41.53 \pm 4.64$ years for male subjects and $41.19 \pm 4.91$ years for female subjects). Majority of the participants were vegetarians $(52.66 \%)$ while the rest $47.33 \%$ were non-vegetarians. Among vegetarians, the proportion of lacto-vegetarians was higher than the Ovo-Lacto vegetarians $(72.15 \%$ and 31.64 $\%$ respectively). The nuclear family set up was predominantly seen as $66 \%$ of the subjects belonged to nuclear families while only $34 \%$ had a joint family setup. The data is typical of an Indian urban setup. As far as religion is considered, the majority of the participants were Hindus $(69 \%)$ followed by others like Muslims $(13 \%)$, Christians $(17 \%)$ and Sikhs $(1 \%)$.

Table 1 highlights the anthropometric profile of the respondents. The mean BMI of the study subjects was reported to be $27.77 \pm 2.68 \mathrm{~kg} /$ $\mathrm{m}^{2}\left(28.4 \pm 3.28 \mathrm{~kg} / \mathrm{m}^{2}\right.$ vs $27.06 \pm 1.53 \mathrm{~kg} / \mathrm{m}^{2}$ for male and female subjects respectively). Since the subjects recruited were all obese, this is well depicted in their distorted anthropometric profile. Means for anthropometric indices like waist to height and waist to hip ratio were higher than the reference cut off points for both the genders.

The mean values for the lipid parameters that is, total cholesterol, triglycerides, and LDL for the total study subjects were reported to be $173.22 \pm 24.73 \mathrm{mg} / \mathrm{dl}, 164.52 \pm 64.79 \mathrm{mg} / \mathrm{dl}$, $96.91 \pm 25.22 \mathrm{mg} / \mathrm{dl}$ respectively. Mean HDL for male and female subjects was $42.40 \pm 4.56 \mathrm{mg} /$ $\mathrm{dl}$ and $44.58 \mathrm{mg} / \mathrm{dl}$ respectively. Gender wise stratification of the results (Table 2) showed that there existed a significant difference in the mean triglycerides (p-0.04*) and HDL levels (p- $\left.0.000^{*}\right)$ among obese male and female subjects.

The modified National Cholesterol Education Program-Adult Treatment Panel-III (NCEP 2002) reference values were applied to classify lipid parameters and assess dyslipidemia. In the present study, the prevalence of dyslipidemia was assessed to be $78 \%$ (Figure 1).

The prevalence was higher in obese female subjects in comparison to the obese male subjects (that is, $81.43 \%$ and $75 \%$ respectively). The difference, however, was statistically insignificant (p-value 0.34). The results are of great concern as the subjects were apparently healthy with no prior history of any chronic diseases.

Figure 2 further distributes subjects according to the abnormal lipid parameter. The prevalence of elevated total cholesterol, triglycerides, low high-density lipoprotein cholesterol and low-density lipoprotein cholesterol was observed to be $12.66 \%, 49 \%$, $52.66 \%$, and $39.33 \%$ respectively. In females, low HDL was the most prevalent deranged lipid parameter $(81.43 \%)$ followed by elevated triglycerides (41.43\%) and high LDL levels $(40 \%)$. In the case of men, however, high

Table 1. Anthropometric profile of the subjects

\begin{tabular}{lccc}
\hline & Males $(\mathrm{n}=80)$ & Females $(\mathrm{n}=70)$ & $\mathrm{p}$-value \\
\hline Age $($ years $)$ & $41.53 \pm 4.64$ & $41.19 \pm 4.91$ & 0.66 \\
Height $(\mathrm{cm})$ & $165.5 \pm 8.52$ & $155.76 \pm 6.21$ & $<0.001^{*}$ \\
Weight $(\mathrm{kg})$ & $77.83 \pm 8.52$ & $65.69 \pm 5.57$ & $<0.001^{*}$ \\
Waist circumference $(\mathrm{cm})$ & $94.04 \pm 11.77$ & $91.24 \pm 6.41$ & 0.07 \\
Hip circumference $(\mathrm{cm})$ & $102.42 \pm 8.54$ & $104.46 \pm 5.71$ & 0.09 \\
Body mass index $\left(\mathrm{kg} / \mathrm{m}^{2}\right)$ & $28.4 \pm 3.28$ & $27.06 \pm 1.53$ & $0.002^{*}$ \\
Waist /hip ratio & $0.92 \pm 0.07$ & $0.88 \pm 0.07$ & $0.000^{*}$ \\
Waist /height ratio & $0.57 \pm 0.07$ & $0.59 \pm 0.04$ & 0.08 \\
\hline
\end{tabular}


Table 2. Lipid profile of the subjects

\begin{tabular}{lccc}
\hline \multicolumn{1}{c}{ Lipid parameter $(\mathrm{mg} / \mathrm{dl})$} & Males $(\mathrm{n}=80)$ & Females $(\mathrm{n}=70)$ & $\mathrm{p}$-value \\
\hline Cholesterol & $173.96 \pm 25.42$ & $172.38 \pm 24.10$ & 0.69 \\
Triglycerides & $174.32 \pm 71.26$ & $153.32 \pm 54.90$ & $0.04^{*}$ \\
High-density lipoprotein & $42.40 \pm 4.5$ & $44.58 \pm 5.56$ & $0.00^{*}$ \\
Low-density lipoprotein & $96.87 \pm 24.61$ & $96.96 \pm 26.09$ & 0.98 \\
\hline
\end{tabular}

triglycerides levels $(56.25 \%)$ followed by high LDL (38.75\%) and low HDL levels $(27.50 \%)$ were the most common deranged parameters. It was interesting to note here that high cholesterol was not common among these obese adults. Only $12.67 \%$ of the total subjects were reported to be hypercholesterolemic $(14.29 \%$ and $11.25 \%$ of males and females respectively). Figure 3 further distributes subjects with dyslipidemia for the presence of several abnormal blood-lipid parameters as per NCEP ATP III guidelines. As many as $29.91 \%$ of the total obese adults had a presence of any one of the lipid parameter that was deranged (viz. $36.67 \%$ in men and $22.81 \%$ women).

Almost half of them (49.57\%) had the presence of any two abnormal lipid parameters, while $5.98 \%$ of them had abnormalities in all the four lipid parameters. A similar pattern was observed when data were stratified based on gender where the majority of obese men $(52.63 \%)$ and women $(46.67 \%)$ had the presence of any two abnormal lipid parameters. Greater number of female participants had the presence of any 3 abnormal lipid parameters (that is $21.05 \%$ in females and $8.33 \%$ in males).

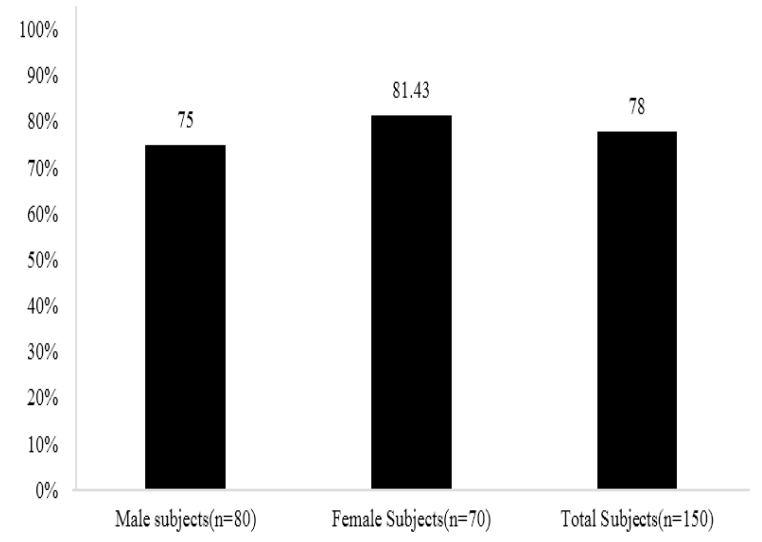

Figure 1. Prevalence of dyslipidemia in the subjects
The present study reports a high prevalence of dyslipidemia (78\%) among apparently healthy urban obese adults. The study results agree with many other studies that highlight the substantial burden of dyslipidemia in India.

The overall prevalence of dyslipidemia in India ranges from $10 \%$ to $73 \%$ depending on the area of residence (rural vs. urban), socioeconomic strata (high vs. middle low), diet and physical activity patterns and age (Ranganathan et al. 2015).

Numerous studies have documented the prevalence of various forms of lipid disorders among Indians. Not only is the prevalence of dyslipidemia high among Indians, but it has also steadily increased in recent decades. Adults who are obese also have a greater risk of establishing dyslipidemia and associated health problems. Recent research has shown that adults with severe obesity may have a lower life expectancy of 1520 years than individuals who are normal weight. In obese adults, a large proportion of morbidity and mortality is attributed to sudden cardiac arrest and congestive heart failure which is associated with obesity (Chitra et al. 2012). Gupta et al. (2008) reported a significant association between increasing dyslipidemias with increasing obesity and truncal obesity

Indian dyslipidemic adults are often characterized by having significantly lower highdensity lipoprotein cholesterol and elevated triglyceride levels (Dalaal et al. 2016). The same characteristics were reported in the present study where low HDL levels and high triglycerides were the most common abnormal lipid parameters. The ICMR-INDIAB study that was conducted in four Indian states (i.e., Maharashtra, Jharkhand, Tamil Nadu and Jharkhand ) reported that despite the regional differences, low HDL-C was the most common lipid abnormality in all the four regions studied and $44.9 \%$ had isolated low HDL cholesterol (Joshi et al. 2014). This study thus confirms the findings of several earlier 


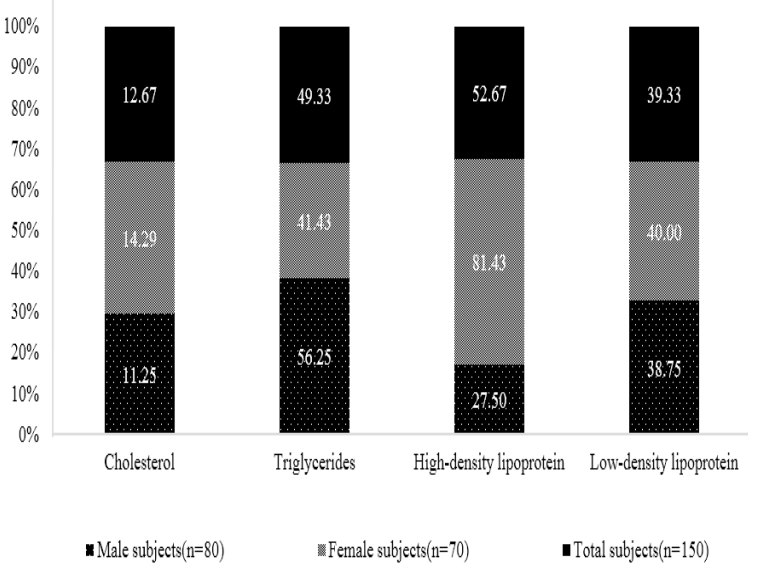

Figure 2. Distribution of subjects based on the abnomal lipid parameter

studies that Indians have a high prevalence of low HDL cholesterol. This appears to be part of the Asian Indian phenotype (Deepa et al. 2006). Ranganathan et al. (2015) reported a high prevalence of dyslipidemia in the obese adults in comparison to adult with normal BMI in Salem, Tamil Nadu. Among the high BMI group, 59\% had hypercholesterolemia, 42\% had HDL-C of $<30 \mathrm{mg} / \mathrm{dl}, 41 \%$ had LDL-C of $>130 \mathrm{mg} / \mathrm{dl}, 56 \%$ had very-low-density lipoprotein (VLDL)-C of $>40 \mathrm{mg} / \mathrm{dl}$ and $55 \%$ had TG $>150 \mathrm{mg} / \mathrm{dl}$.

One of the characteristic features of obesityrelated dyslipidemia is elevated fasting and postprandial TG combined with the prevalence of small dense LDL and lower levels of HDL-C (Klop et al. 2013), Indians and migrant from South Asia tend to have higher triglyceride levels and lower HDL cholesterol with lower total cholesterol levels than in the general population in the US and the UK (McKeigue et al. 1989; Enas 2000). This is in concordance with the present study as high cholesterol was the least prevalent abnormal lipid parameter among the subjects. Data from the western countries illustrates that total cholesterol is the most common deranged lipid parameter and unlike South Asians, they are reported to have better HDL levels. In recent research among Asian Indian immigrants in the United States, it was noted that the prevalence of hypercholesterolemia was $43.5 \%$, while that of hypertriglyceridemia of $42.3 \%$, low HDL and high LDH were $42.3 \%, 26.4 \% 41.4 \%$ respectively

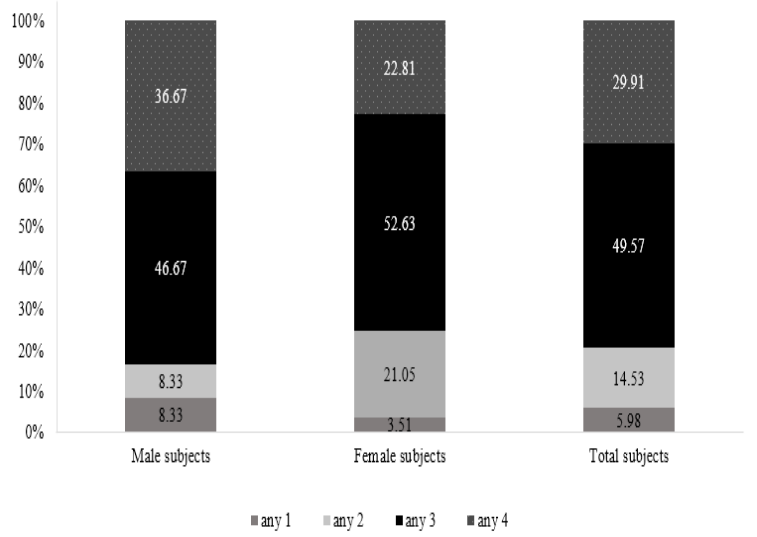

Figure 3. Distribution of the dyslipidemic subjects with number of abnormal bloodlipid parameters present by NCEPATP III Guidelines

(Misra et al. 2010). Jordanian adults reported similar prevalence rates, with a prevalence of $48.8 \%$ hypercholesterolemia, $43.6 \%$ hypertriglyceridemia, 40.1\% low HDL-C and 40.7\% high LDL-C (Khader et al. 2010). Among Turkish adults also the prevalence rates were much similar that is, hypercholesterolemia (37.5\%), high triglycerides (30.4\%), low HDL-C (21.1.\%) and high LDL-C (44.5\%) (Erem et al. 2008).

\section{CONCLUSION}

The study result highlights the high prevalence of dyslipidemia (78\%) among adult obese subjects who were apparently healthy. It was observed that low HDL levels and high triglycerides were the most common abnormal lipid parameters. The results are of great concern as the subjects had no prior history of any chronic diseases. The high prevalence among asymptomatic urban adults emphasizes the importance of regular and timely screening for apparently healthy populations and further advocating adequate medical and dietary intervention that can help in controlling and preventing health-related complications.

\section{ACKNOWLEDGEMENT}

The authors would like to acknowledge all the participants for giving consent to be a part of this study. H.K. developed the theoretical 
formalism and drafted the manuscript. Both H.K and BTA contributed to the final version of the manuscript. BTA supervised the project.

\section{AUTHOR DISCLOSURES}

The authors have no conflict of interest.

\section{REFERENCES}

Ashwell M, Gibson S. 2016. Waist-to-height ratio as an indicator of "early health risk': Simpler and more predictive than using a 'matrix' based on BMI and waist circumference. BMJ Open 6(3):e010159. doi:10.1136/bmjopen-2015-010159.

Bilen O, Kamal A, Virani S. 2016. Lipoprotein abnormalities in South Asians and its association with cardiovascular disease: Current state and future directions. World J Cardiol 8(3):247-257. doi: 10.4330/wjc. v8.i3.247.

Burstein M, Scholnick HR, Morfin R. 1970. Rapid method for the isolation of lipoproteins from human serum by precipitation with polyanions. J Lipid Res 11(6):583-595.

Chandra KS, Bansal M, Nair T, Iyengar SS, Gupta R, Manchanda SC, Mohanan PP, Rao VD, Manjunath CN, Sawhney JPS et al. 2014. Consensus statement on management of dyslipidemia in Indian subjects. Indian Heart J 66(Suppl 3):S1-S51. doi:10.1016/j. ihj.2014.12.001.

Chitra U, Reddy N, Balakrishna N. 2012. Role of lifestyle variables on the lipid profile of selected South Indian subjects. Indian Heart J 64(1):28-34. https://doi.org/10.1016/ S0019-4832(12)60007-8.

Dalal J, Deb PK, Shrivastava S, Rao MS, Mohan JC, Kumar AS. 2016. Vascular disease in young Indians (20-40 years): Role of dyslipidemia. J Clin Diagn Res 10(7):OE01-OE5. doi:10.7860/ JCDR/2016/18683.8191.

Deepa R, Sandeep S, Mohan V .2006. Abdominal Obesity, Visceral Fat and Type 2 Diabetes - "Asian Indian Phenotype". In: Mohan V, Gundu HR Rao, editors. Type 2 Diabetes in South Asians: Epidemiology, Risk Factors and Prevention. New Delhi (IN): Jaypee Brothers Medical Publishers.
Dyslipidemia in healthy Indian urban obese adults

Dewi M. 2007. Resistensi insulin terkait obesitas: Mekanisme endokrin dan intrinsik sel. J Gizi Pangan 2(2):49-54. doi: 10.25182/ jgp.2007.2.2.49-54.

Enas EA, Garg A, Davidson M, Nair V, Huet B, Yusuf S. 1996. Coronary heart disease and its risk factors in first-generation immigrant Asian Indians to the United States of America. Indian Heart J 48(4): 343-353.

Enas EA. 2000. Coronary artery disease epidemic in Indians: A cause for alarm and call for action. JIndian MedAssoc 98(11):697-702.

Enas EA, Dharmarajan T, Varkey B. 2015. Consensus statement on the management of dyslipidemia in Indian subjects: A different perspective. Indian Heart J 67(2): 95-102. doi: 10.1016/j.ihj.2015.03.020.

Erem C, Hacihasanoglu A, Deger O, Kocak M, Topbas M. 2008. Prevalence of dyslipidemia and associated risk factors among Turkish adults: Trabzon lipid study. Endocrine 34(1-3):36-51. https:// doi.org/10.1007/s12020-008-9100-z.

Feingold KR, Grunfeld C. 2000. Obesity and dyslipidemia. In: De Groot LJ, et al editors. Endotext. South Dartmouth (USA): MDText.com, inc.

Friedewald WT, Levy RI, Fredrickson DS. 1972. Estimation of the concentration of low-density lipoprotein cholesterol in plasma, without use of the preparative ultracentrifuge. Clin Chem 18(6):499-502. https://doi.org/10.1093/ clinchem/18.6.499.

Gupta R, Rao R. S, Misra A, Sharma SK. 2017. Recent trends in epidemiology of dyslipidemias in India. Indian Heart J 69(3): 382-392. doi:10.1016/j.ihj.2017.02.020.

Howard BV, Ruotolo G, Robbins DC. 2003. Obesity and dyslipidemia. Endocrin Metab Clin 32: 855-867. doi: 10.1016/s08898529(03)00073-2.

[IIPS] International Institute for Population Sciences and ICF. 2017. National Family Health Survey (NFHS-4) 2015-16: India. Mumbai (IN): IIPS.

Jacob BS, Balachandran J, Paul B. 2014. A study on prevalence of dyslipidemia in obese patients in a teaching hospital in Kerala. Sch J Appl Med Sci 2(2B): 642-646.

Joshi SR, Anjana RM, Deepa M, Pradeepa R, Bhansali A, Dhandania VK, Joshi PP, 
Unnikrishnan R, Nirmal E, Subashini R, et al. 2014. Prevalence of dyslipidemia in urban and rural India: The ICMR-INDIAB study. Plos One 9(5):e96808. doi:10.1371/ journal.pone.0096808.

Khader YS, Batieha A, El-Khateeb M, Al Omari MA, Ajlouni K. 2010. Prevalence of dyslipidemia and its associated factors among Jordanian adults. J Clin Lipidol 4(1):53-58. doi:10.3390/nu5041218. https://doi.org/10.1016/j.jacl.2009.12.004.

Klop B, Elte JW, Cabezas MC. 2013. Dyslipidemia in obesity: Mechanisms and potential targets. Nutrients 5(4):1218-1240. https:// doi.org/10.3390/nu5041218.

Mahajan K, Batra A. 2018. Obesity in adult asian indians- the ideal BMI cut-off. Indian Heart J 70(1):195-196. http://dx.doi. org/10.1016/j.ihj.2017.11.00.

McKeigue P, Miller GJ, Marmot MG. 1989. Coronary heart disease in South Asians overseas: A review. J Clin Epide iol 42(7):597-609. doi: 10.1016/08954356(89)90002-4.

Misra A, Khurana L. 2010. Obesity-related noncommunicable diseases: South Asians vs White Caucasians. Int J Obes 35(2):167187. doi: 10.1038/ijo.2010.135.

Misra A, Chowbey P, Makkar BM, Vikram, NK, Wasir JS, Chaddha D, Joshi SR, Sadikot S, Gupta R, Gulati S, Munjal YP. 2009. Consensus statement for diagnosis of obesity, abdominal obesity and the metabolic syndrome for Asian Indians and recommendations for physical activity, medical and surgical management. J Assoc Physicians India 57:163-170.

Misra A, Luthra K, Vikram NK. 2004. Dyslipidemia in Asian Indians: Determinants and significance. J Assoc Physicians India 52:137-142.

Misra R, Patel T, Kotha P, Raji A, Ganda O, Banerji M, Shah V, Vijay K, Mudaliar S, Iyer D, Balasubramanyam A. 2010. Prevalence of diabetes, metabolic syndrome, and cardiovascular risk factors in US Asian Indians: Results from a national study. J Diabetes Complication 24(3):145-153. https://doi.org/10.1016/j. jdiacomp.2009.01.003.

McGowan M, Artiss J, Strandbergh D, Zak, B. 1983. A peroxidase-coupled method for the colorimetric determination of serum triglycerides. Clin Chem
29(3):538-542. https://doi.org/10.1093/ clinchem/29.3.538.

[NCEP] National Cholesterol Education Program. 2002. Third report of the national cholesterol education program (NCEP) expert panel on detection, evaluation, and treatment of high blood cholesterol in adults (adult treatment panel III). Final report. Circulation 106(25):3143-3421. doi: 10.1161/circ.106.25.3143.

Pradeepa R, Anjana RM, Joshi SR, Bhansali A, Deepa M, Joshi PP, Dhandania VK, Madhu SV, Rao P,V Geetha L, et al. 2015. Prevalence of generalized \& abdominal obesity in urban \& rural India- the ICMR - INDIAB Study (Phase-I) [ICMRINDIAB-3]. Indian J Med Res 142(2):139. doi: 10.4103/0971-5916.164234.

Patel JV, Caslake MJ, Vyas A, Cruickshank JK, Prabhakaran D, Bhatnagar D, Reddy KS, Lip GYH, Mackness MII, et al. 2010. Triglycerides and small dense low density lipoprotein in the discrimination of coronary heart disease risk in South Asian populations. Atherosclerosis 209(2): 579-584. doi: 10.1016/j. atherosclerosis.2009.10.010.

Ranganathan S, Krishnan TU, Radhakrishnan S. 2015.Comparison of dyslipidemia among the normal-BMI and high-BMI group of people of rural Tamil Nadu. Med J DY Patil Univ 8(2):149-52.

Roeschalu P, Bernt E, Gruber W. 1974. Enzymatic determination of total cholesterol on serum. Z Klin Chem Klin Biochem 12(5):226.

SharobeemKM,PatelJV,RitchAES,LipGYH,Gill P,S Hughes EA. 2007. Elevated lipoprotein (a) and apolipoprotein b to al ratio in South Asian patients with ischaemic stroke*. Int J Clin Pract Suppl 61(11):1824-1828. doi: 10.1111/j.1742-1241.2007.01521.x.

Vekic J, Zeljkovic A, Stefanovic A, Jelic-Ivanovic Z, Spasojevic-Kalimanovska V. 2019. Obesity and dyslipidemia. Metabolism 92:71-81. https://doi.org/10.1016/j. metabol.2018.11.005.

[WHO] World Health Organization. Obesity. 2019. https://www.who.int/topics/obesity/ en/ [Accessed 16 th May 2019].

[WHO] World Health Organization. 2011. Waist Circumference and Waist-Hip Ratio: Report of a WHO Expert Consultation. Geneva, 8-11 December 2008. Geneva $(\mathrm{CH})$ : World Health Organization. 